\title{
AVALIAÇÃO QUALITATIVA DA PRODUÇÃO DE LIPASES E BIOSSURFACTANTES POR FUNGOS ISOLADOS DE RESÍDUOS OLEOSOS
}

\author{
João G. C. Sperb ${ }^{1}$ \\ Tania M. Costa ${ }^{2}$ \\ Deisi A. $\mathrm{Vaz}^{3}$ \\ José A. B. Valle \\ Rita de Cássia S. C. Valle ${ }^{5}$ \\ Lorena B. B. Tavares ${ }^{6}$
}

\begin{abstract}
Resumo: A busca por novos microrganismos produtores de compostos enzimáticos e tensoativos é de interesse estratégico. Este estudo verificou a produção de lipases e biossurfactantes por fungos filamentosos isolados de resíduos de refinarias de óleo vegetal e de petróleo. A presença e a qualidade de lipases ao final do processo fermentativo foram estudadas por meio de dois métodos qualitativos: (i) um ensaio de placas, o qual detecta a formação de um halo fluorescente laranja devido à hidrólise do substrato oleoso na presença de rodamina B; (ii) por adição de Tween 80 solúvel em água em um meio nutriente e verificação de um halo opaco visível ao redor da colônia, indicativo da hidrólise do éster. A partir dos 24 fungos isolados e estudados, apenas 2 indicaram resultados positivos em ambos os testes enzimáticos. Com relação à produção de biossurfactante, 12 fungos apresentaram resultados positivos tanto para o teste de atividade hemolítica como para o ensaio com microplacas, baseado no efeito da forma do menisco sobre uma imagem quadriculada vista através das cavidades de uma placa de 96 poços. As cepas identificadas como Aspergillus niger (LEB 025) e Rhizopus sp. (LEB 037 e 044), demonstraram potencial para a produção de ambos os compostos de interesse e, devido a esses motivos, podem ser utilizados em estudos posteriores de otimização e aumento de escala do bioprocesso.
\end{abstract}

Palavras chave: Fungos filamentosos, Lipases, Biossurfactante.

Abstract: The search for new microorganisms with the ability to produce enzymes and surfactants is of strategic interest. In this work we have investigated the production of lipases and biosurfactants by filamentous fungi isolated from wastes generated by a vegetable oil extraction plant and a crude oil refinery. The presence of lipases at the end of the fermentation process was studied by two qualitative methods: (i) a plate assay which detects the formation of orange fluorescent halos due the hydrolysis of the oily substrate in presence of rhodamine B; (ii) by monitoring the presence of an opaque visible halo around microorganism colonies due to hydrolysis of Tween 80 in agar medium. Among the 24 strains examined only 2 yielded positive results in both lipase production tests. Regarding biosurfactant production, 12 strains gave positive results for both hemolytic activity test and a microplate assay based on the effect of meniscus shape on the image of a grid viewed through the wells of a 96-well plate. The strains identified as Aspergillus niger (LEB 025) and Rhizopus sp. (LEB 037 and 044) demonstrated potential for production of both compounds of interest and, due to these reasons, they can be used in further studies of optimization and scale-up.

\footnotetext{
${ }^{1}$ Universidade Regional de Blumenau, E-mail: joaosperb@gmail.com.

${ }^{2}$ Universidade Regional de Blumenau, E-mail: tmcosta02@gmail.com.

${ }^{3}$ Universidade de Granada, E-mail: deisiav@ugr.es.

${ }^{4}$ Universidade Federal de Santa Catarina, E-mail: alex@furb.br.

${ }^{5}$ Universidade Federal de Santa Catarina, E-mail: rscurtovalle@gmail.com.

${ }^{6}$ Universidade Regional de Blumenau, E-mail: lorena@furb.br
} 
Keywords: Filamentous fungi, Lipase, Biosurfactant.

\section{INTRODUÇÃO}

As enzimas lipolíticas Lipases (triacilglicerol acil hidrolases, E.C.3.1.1.3) e Esterases (E.C.3.1.1.1) pertencem a um grupo de enzimas cuja função biológica é o de catalisar a hidrólise de triglicerídeos, bem como reações de esterificação, transesterificação e interesterificação de lipídios (Martins et al. 2008; Colla et al. 2010; Kumar et al. 2012). As lipases e esterases podem ser distinguidas com base em seus espectros de substratos. As lipases verdadeiras tem preferência em catalisar a hidrólise de ácidos graxos de cadeia longa ( $\geq 10$ carbonos), enquanto as esterases tem preferência por ligações de ésteres de ácidos carboxílicos de cadeia curta $(<10$ carbonos) (Chahiniana e Sarda 2009; Kumar et al. 2012). As lipases podem ser de origem animal, vegetal e microbiana (Cardenas et al. 2001). As lipases de origem microbiana possuem potencial para uma variedade de aplicações de uso industrial, na produção de alimentos e detergentes, no tratamento biológico de águas residuárias, em medicamentos e cosméticos (Burkert, Maugeri e Rodrigues, 2004; Roveda, Hemkemeier e Colla, 2010), devido a sua estabilidade, seletividade e ampla especificidade de substrato, sendo estas, as mais usuais (Cardenas et al. 2001; Martins et al. 2008; Colla et al. 2010). As lipases também podem ser utilizadas para produção de biossurfactantes através de síntese orgânica, que catalisa a esterificação dos ácidos graxos e açúcares (Colla et al. 2010).

Os biossurfactantes ou surfactantes de origem microbiana são, em sua maioria, uma classe de metabólitos secundários que compreendem um grupo de moléculas anfipáticas com estruturas químicas distintas, sintetizadas por uma variedade de microrganismos (Desai e Banat 1997; Gudiña et al. 2013). Devido a presença de grupos hidrofílicos e hidrofóbicos na mesma molécula, os biossurfactantes tendem a se distribuir e atuar em interfaces entre dois fluidos imiscíveis (Nitschke e Pastore 2002; Martins et al. 2008; Castiglioni et al. 2009; Gasparin et al. 2012; Saharan et al. 2012), incluindo a habilidade de diminuir a tensão superficial da água (Araujo e Freire 2013). Estas propriedades fazem destas moléculas ideais para uma ampla gama de aplicações industriais, que envolvem emulsificação, lubrificação, capacidade espumante, capacidade molhante, detergência, solubilização e dispersão de fases (Nitschke e Pastore 2002; Araujo e Freire 2013).

Dentre as principais vantagens dos biossurfactantes, em relação aos surfactantes sintéticos, destacam-se a baixa toxicidade e a alta biodegradabilidade, (Araujo e Freire 2013) estabilidade e funcionalidade a condições extremas de $\mathrm{pH}$, temperatura e concentração de sais (Colla et al, 2010). Sua ação antimicrobiana e de caráter antiadesiva contra patógenos são relevantes para aplicações relacionadas a saúde (Gudiña et al. 2013).

A busca por novos microrganismos isolados de distintos ambientes, em especial os não tóxicos ao organismo humano, é de interesse estratégico, pois além de tornar possível o desenvolvimento de novos sistemas de produção enzimática (Roveda et al., 2010) e de biotensoativos, pode minimizar os impactos ambientais causados pela síntese destes compostos nos tratamentos convencionais.

Microrganismos com potencial para a produção de lipases e biossurfactantes vêm sendo isolados de diversos ambientes, dentre os quais se destacam resíduos industriais de processamento de óleos vegetais e de laticínios, solos contaminados com óleos, dentre outros (Gasparin et al. 
2012; Pacheco 2012). Hidrocarbonetos de petróleo vêm sendo mencionados como substratos com potencial para a produção microbiana de enzimas comercialmente viáveis e metabólitos secundários (Martins et al. 2008). A síntese de lipases e biossurfactantes por microrganismos ocorre mediante a necessidade de metabolizar os compostos presentes nos meios aos quais estão submetidos (Colla $e t$ $a l, 2010)$.

Os fungos filamentosos se destacam na produção de inúmeros compostos de importância econômica, comercial e biotecnológica, devido a diversidade de ambientes nos quais se adaptam (Esposito e Azevedo 2004; Cortés e Mosqueda 2013). As lipases e os compostos de metabolismo secundário, com destaque para antibióticos, que possuem aplicação industrial são, em sua maioria, produzidos por fungos filamentosos (Pacheco 2012; Cortés e Mosqueda 2013). Aspergillus fumigatus (Castiglioni et al. 2009), Aspergillus niger (Matsuura 2004), Aspergillus sp.(Colla et al. 2012), Pleurotus ostreatus (Matsuura 2004), Ustilago maydis (Spoeckner et al. 1999), Penicillium sp. ( Cortés e Mosqueda 2013), Polyporus sulphureus (Arun e Eyini 2011), Curvularia luneta (Paraszkiewicz et al. 2012), Phellinus sp. (Arun e Eyini 2011), Thricoderma (Colla et al. 2012) e Agaricus campestris (Matsuura 2004) são exemplos de alguns fungos filamentosos utilizados para obtenção de biossurfactantes. Fungos do gênero Penicillium, Aspergillus, e Curvularia, apresentam resultados favoráveis na produção de lipases (Rapp e Backhaus 1992), sendo microrganismos produtores simultâneos de lipases e biossurfactantes.

Tendo em vista a grande diversidade de compostos produzidos pelos fungos e sua importância econômica e ambiental, objetivou-se isolar fungos filamentosos a partir de amostras de resíduo do refino de óleo vegetal e de refino de petróleo e avaliar por métodos qualitativos, a produção de lipases e biossurfactantes.

\section{MATERIAL E MÉTODOS}

\subsection{Isolamento e armazenamento dos fungos}

Os fungos foram isolados de duas amostras de resíduos procedentes de uma planta de refino de óleo vegetal situada em Gaspar - SC, além de uma amostra de uma refinaria de petróleo, situada em Canoas RS. Os resíduos do refino de óleo vegetal foram coletados no flotador da Estação de Tratamento de Efluentes (ETE).

Para cada amostra, suspendeu-se um grama de amostra em $9 \mathrm{~mL}$ de uma solução de Tween 80 (8 g. $\left.\mathrm{L}^{-1}\right)$, e em seguida foram agitadas em vórtex com velocidade máxima por 2 minutos. Diluições em série foram realizadas $\left(10^{-4}\right)$, sendo uma alíquota de $0,1 \mathrm{~mL}$ de cada diluição colocada em placas com meio Dicloran Cloranfenicol Rosa Bengala (DRBC - Kasvi) para inibir a contaminação bacteriana. As placas DRBC foram incubadas a $25^{\circ} \mathrm{C}$ por 7 dias. Sucessivas inoculações foram realizadas na etapa de isolamento em ágar batata dextrose (BDA - KASVI) até obtenção de culturas axênicas. Todos os isolados foram armazenados a temperatura de $4^{\circ} \mathrm{C}$ em meio BDA com repique realizado a cada 2 meses.

\subsection{Presença de lipases em óleo vegetal e rodamina $b$}

$\mathrm{O}$ teste qualitativo de atividade de lipases em meio com o corante rodamina B foi realizado em placas seguindo o método modificado de Kouker e Jaeger (1987). O meio foi constituído por rodamina $\mathrm{B}$ $0,001 \%(\mathrm{~m} / \mathrm{v})$, caldo nutriente $\left(8\right.$ g. $\left.\mathrm{L}^{-1}\right)$, $\mathrm{NaCl}\left(4\right.$ g.L $\left.\mathrm{L}^{-1}\right)$, ágar $\left(10\right.$ g.L $\left.\mathrm{L}^{-1}\right)$ e óleo de soja $2,5 \% \quad(\mathrm{~m} / \mathrm{v})$. Os isolados foram inoculados individualmente no centro de cada placa e incubados a $25^{\circ} \mathrm{C}$ por 5 dias, sendo então analisadas sob luz ultravioleta de $365 \mathrm{~nm}$. Os resultados foram considerados positivos para os meios que apresentaram fluorescência alaranjada em presença de luz ultravioleta, proveniente da 
ativação interfacial ocasionada pela reação enzimática. Os testes foram realizados em triplicatas.

\subsection{Teste de hidrólise de ésteres com tween 80}

Para o teste de hidrólise de ésteres, foi utilizada a metodologia modificada de Sierra (1957), em meio contendo Tween 80. O meio disperso em placas de Petri foi constituído por bacto peptona $\left(10\right.$ g. $\left.\mathrm{L}^{-1}\right)$, $\mathrm{NaCl}\left(5\right.$ g. $\left.\mathrm{L}^{-1}\right), \mathrm{CaCl}_{2} \cdot \mathrm{H}_{2} \mathrm{O}\left(0,1\right.$ g. $\left.\mathrm{L}^{-1}\right)$ e Tween $80\left(10 \mathrm{~mL} \cdot \mathrm{L}^{-1}\right)$. Cada fungo foi inoculado individualmente no centro de cada placa e incubados a $25^{\circ} \mathrm{C}$ por 5 dias. A visualização de um halo opaco ao redor das colônias foi indicativa de resultado positivo devido ao sal de cálcio, insolúvel em ácidos graxos, provenientes da hidrólise do éster. Os testes foram realizados em triplicatas.

\subsection{Presença de hemólise em ágar sangue}

A presença de biossurfactante pelo teste de hemólise foi realizado em placas seguindo o método descrito por Carillo et al. (1996). O meio foi constituído por ágar sangue base $\left(40\right.$ g. $\left.\mathrm{L}^{-1}\right)$ suplementado com $5 \% \quad(\mathrm{v} / \mathrm{v})$ de sangue de carneiro desfibrinado. Cada fungo foi inoculado individualmente no centro de cada placa e incubados a $25^{\circ} \mathrm{C}$ por 5 dias. A presença de um halo transparente ao redor das colônias indica a produção de biossurfactante. Os testes foram feitos em triplicatas.

\subsection{Cultivo submerso para síntese de biossurfactante}

Foram realizados os cultivos de cada isolado em erlenmeyers de $250 \mathrm{~mL}$ contendo $100 \mathrm{~mL}$ de meio extrato de malte 2,5\% (m/v). Um disco de micélio de $9 \mathrm{~mm}$ de cada fungo foi adicionado aos frascos e agitados $(200 \mathrm{rpm})$ a $25^{\circ} \mathrm{C}$ por 14 dias. A extração do biossurfactante foi realizada pela centrifugação do caldo a $6.000 \mathrm{rpm}$ e $4^{\circ} \mathrm{C}$ durante 15 minutos, sendo o sobrenadante livre de células utilizado para os testes de distorção ótica e tensão superficial. Os cultivos foram realizados em triplicata.

\subsection{Teste da distorção ótica}

O método de indicação da presença de biossurfactante foi realizado conforme descrito por Chen et al. (2007). Uma amostra de $100 \mu \mathrm{L}$ do sobrenadante livre de células foi transferida para poços de placa de Elisa (em triplicata) e sobrepostas a um papel milimetrado. Para fins de comparação entre os resultados, foi realizada uma alternância dos poços entre água destilada e as amostras dos caldos. A diminuição significativa da imagem da amostra, em relação à imagem do poço com água destilada é indicativo da presença de biossurfactante.

\subsection{Tensão superficial}

A tensão superficial do sobrenadante proveniente do cultivo submerso foi determinada a $25{ }^{\circ} \mathrm{C}$ utilizando um Tensiômetro Interfacial KRÜSS K8, através do sistema de medidas com anel de platina Du Nouy, em triplicatas. Os resultados de tensão superficial foram submetidos a Análise de Variância (ANOVA) e Teste de Tukey ao nível de $5 \%$ de significância para a comparação entre as médias.

\subsection{Identificação dos fungos produtores de lipases e biossurfactantes}

Todos os fungos isolados foram classificados segundo a morfologia macroscópica de acordo com a textura, relevo, bordas, coloração e aspecto. Já os fungos que apresentaram resultados positivos no teste de presença de lipase e em ambos os testes de produção de biossurfactantes, foram submetidos a análises microscópicas, utilizando um microscópio eletrônico de varredura (MEV), (VEGA 3, TESCAN,) 
reproduzindo imagens de alta ampliação e resolução da pequena fração fúngica retirada da placa de Petri. A identificação dos fungos foi realizada no Laboratório de Micologia, do Departamento de Farmácia (FURB).

\section{RESULTADOS E DISCUSSÃO}

\subsection{Fungos isolados}

Foram isolados 24 fungos filamentosos a partir dos resíduos das refinarias utilizados, sendo nomeados com a sigla "LEB" e numerados de 022 até 045. Do total de morfotipos isolados, 16 foram coletados do resíduo procedente da refinaria de petróleo e 8 foram isolados do resíduo do refino de óleo vegetal. Dentre os fungos isolados, algumas características macroscópicas das colônias foram observadas, constatando-se que $31,03 \%$ apresentavam textura algodonosa, 58,62\% com relevo liso, $55,17 \%$ com bordas irregulares, $62,07 \%$ com coloração branca na superfície, $27,59 \%$ com coloração bege claro no verso e 79,31\% com colônias opacas.

Fungos com características similares foram encontrados por Pacheco (2012), que isolou 19 cepas de um efluente de abatedouros de frangos visando à obtenção de uma linhagem selvagem lipolítica. Roveda et al. (2010) apresentaram um isolamento semelhante a partir de um efluente de laticínios, obtendo num total de 21 cepas de fungos, dentre eles, uma levedura, testados quanto à produção de lipases. Dentre os fungos isolados pelos autores, foram identificados como do gênero Aspergillus, Penicillium, Trichoderma e Fusarium pela técnica de microcultivos.

A seleção de microrganismos super produtores ainda é uma técnica de grande importância, em especial, países que apresentam uma biodiversidade como o Brasil (Roveda et al., 2010). A natureza hidrofóbica dos resíduos das refinarias, utilizados no isolamento dos fungos deste estudo, aumenta a probabilidade da existência de microrganismos produtores de lipases e/ou biossurfactantes, o que justifica a busca de novas cepas fúngicas nestes locais.

\subsection{TESTES QUALITATIVOS DA PRESENÇA DE LIPASES}

Os fungos isolados foram sujeitos a uma seleção qualitativa de produção de lipase sobre o óleo vegetal e rodamina B e teste de hidrólise de ésteres com o Tween 80. Diversos fungos apresentaram uma zona de hidrólise ao redor da colônia, conforme Tabela 1, nos quais estão separados por fungos e seus respectivos locais de isolamento. A ação da enzima lipase sobre os triglicerídeos e ésteres de cadeia longa ( $\geq 10$ carbonos) foi verificada no teste com óleo de soja e rodamina $\mathrm{B}$, no qual apresentou 6 resultados positivos (LEB 025，029，033，037，040 e 044), sendo em sua maioria, fungos isolados do resíduo do petróleo. A ação enzimática sobre ésteres de cadeia curta $\quad<10$ carbonos), foi verificada no teste com Tween 80 (Monoooleato de polioxietileno sorbitano - Polissorbato 80), no qual também apresentou 6 resultados positivos (LEB 025, 029, 031, 034, 035 e 043). O Tween 80 é hidrolisado raramente por esterases e principalmente por lipases, uma vez que este contêm ésteres de ácidos oleicos. As esterases hidrolisam facilmente ácidos graxos de cadeia curta, como o Tween 20 (Kumar et al., 2012). As cepas fúngicas LEB 025 e LEB 029 apresentaram resultados positivos em ambos os testes enzimáticos aplicados, o que as torna promissoras, pois suas lipases podem hidrolisar também ésteres que não são triglicerídeos. Neste estudo, os fungos que apresentaram hidrólise, somente em ésteres e não em triglicerídeos, foram desconsiderados quanto a serem produtores de lipases. 
Tabela 1 - Resultados da atividade lipolítica e de produção de biossurfactantes dos fungos isolados no resíduo de refino de petróleo e de refino de óleo vegetal

\begin{tabular}{ccccc}
\hline \multirow{2}{*}{$\begin{array}{c}\text { Isolado } \\
\text { (LEB) }\end{array}$} & $\begin{array}{c}\text { Óleo veg. e } \\
\text { rod. B }\end{array}$ & Tween 80 & Hemólise & $\begin{array}{c}\text { Distorção } \\
\text { ótica }\end{array}$ \\
\hline 022 & - & - & + & + \\
023 & - & - & - & - \\
024 & - & - & + & + \\
025 & + & + & + & + \\
026 & - & - & - & - \\
027 & - & - & - & + \\
028 & - & - & + & + \\
044 & + & - & + & + \\
& & & &
\end{tabular}

\begin{tabular}{ccccc}
\hline \multirow{2}{*}{$\begin{array}{c}\text { Isolado } \\
\text { (LEB) }\end{array}$} & $\begin{array}{c}\text { Óleo veg. e } \\
\text { rod. B }\end{array}$ & Tween 80 & Hemólise & $\begin{array}{c}\text { Distorção } \\
\text { ótica }\end{array}$ \\
\hline 029 & + & + & - & - \\
030 & - & - & + & + \\
031 & - & + & + & + \\
032 & - & - & - & + \\
033 & + & - & - & - \\
034 & - & + & - & + \\
035 & - & + & + & + \\
036 & - & - & + & - \\
037 & + & - & + & + \\
038 & - & - & + & + \\
039 & - & - & - & - \\
040 & + & - & - & - \\
041 & - & - & - & + \\
042 & - & - & - & + \\
043 & - & + & + & + \\
045 & - & - & + & + \\
\hline \multicolumn{7}{c}{} & $(+)=$ indicativo da reação; $(-)=$ ausência de reação
\end{tabular}

\subsection{Testes qualitativos da presença de biossurfactante}

Testes qualitativos podem apresentar diferenças entre si (Youssef et al. 2004). Diante disso, a presença de biossurfactante foi avaliada através do teste de hemólise em placas e no teste de distorção ótica. O teste com microplacas, baseado na metodologia de Chen et al. (2007) compara de forma visual, conforme Figura 1, a presença de surfactante no meio, sendo considerado um indicativo simples e eficiente para esta constatação. Os poços alternados com água pura apresentaram uma superfície plana que adere às paredes da placa. A presença de surfactante no meio aquoso altera a molhabilidade das superfícies ocasionando uma distorção da imagem quadriculada abaixo da placa. 


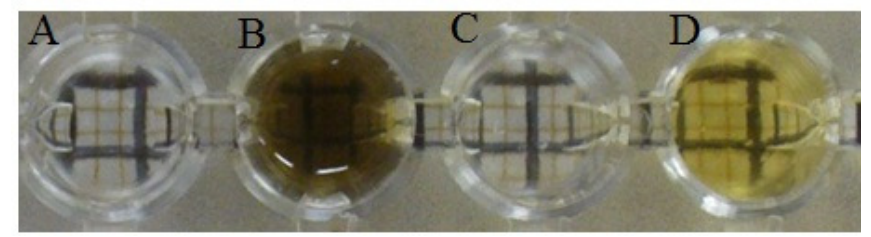

Figura 1. Distorção ótica ocasionada pela presença de biossurfactante no meio fermentado (A) Água pura (B) Resultado indicativo da presença de biossurfactante (C) Água pura (D) Resultado negativo da presença de biossurfactante

De acordo com Chen et al. (2007) este ensaio é sensível, rápido e de fácil execução, podendo ser realizado sem a utilização de equipamentos especializados ou produtos químicos. Conforme Tabela 1, 17 fungos isolados apresentaram distorção ótica na imagem abaixo da placa, indicativo da presença de biossurfactante no meio de cultivo após 14 dias de fermentação.

A formação de halo hemolítico foi evidenciada em 13 cepas (Tabela 1). A seleção de microrganismos produtores de biossurfactante, através do teste de hemólise, vem sendo citada por diversos autores (Mulligan et al., 1984; Banat, 1993; Carillo et al. 1996). De acordo com Youssef et al. (2004), este teste é considerado uma seleção primária de organismos produtores de biossurfactantes, podendo omitir microrganismos produtores destes compostos (Youssef et al. 2004), visto que o mecanismo de hemólise está diretamente relacionado com a estrutura do tensoativo (Alves, 2003). Apesar disso, Plaza et al. (2006) verificaram um alto valor de correlação entre os resultados positivos de hemólise e a redução da tensão superficial num estudo realizado pelos autores.

Neste estudo, o teste de hemólise foi utilizado para reforçar os resultados obtidos no teste da distorção ótica, dos quais 12 fungos apresentaram resultados concomitantes, em ambos os testes aplicados. Os fungos LEB 027, 032, 034, 041 e 042 , apresentaram resultado positivo no teste de distorção ótica e não apresentaram formação de halos hemolíticos. Tal característica pode estar associada ao tipo de tensoativo produzido pelo fungo, não detectável no teste de hemólise. Diante disso, foram considerados microrganismos potenciais na produção de biossurfactantes os que apresentaram resultados positivos em ambos os testes, sendo desconsiderado também o fungo LEB 036 que apresentou indicativo de produção de biossurfactante somente no teste de hemólise.

Ambientes contendo compostos apolares podem propiciar a existência de fungos capazes de se desenvolver produzindo moléculas com características surfactantes (Desai e Banat 1997; Saharan et al. 2012). Neste estudo, $50 \%$ dos fungos isolados (LEB 022, 024, 025, 028, 030, 031, 035, 037, 038, 043, 044 e 045) apresentaram resultados positivos para presença de biossurfactantes em ambos os testes, sendo estes considerados microrganismos com potencial para a produção de moléculas surfactantes.

\subsection{Correlação da presença de lipases e biossurfactante}

Considerando os resultados positivos e critérios estabelecidos de seleção de fungos produtores de lipase e de biossurfactante apresentados na Tabela 1, os fungos LEB 025, 037 e 044, dentro das condições experimentais adotadas, podem ser considerados microrganismos capazes de produzir lipases e biossurfactantes. Dentre estes fungos, o fungo LEB 025, além da ação enzimática sobre os triglicerídeos, apresentou também ação enzimática na hidrólise de ésteres no teste com Tween 80, evidenciando maior aplicação da lipase sintetizada por este 
fungo em distintos processos que envolvam a hidrólise de ésteres.

Martins et al. (2008) em seus estudos de co-produção de lipase e biossurfactante para utilização em biorremediação, utilizando fungos filamentosos, confirmam que é possível a obtenção de lipases e biossurfactantes em um mesmo bioprocesso, demonstrando que a produção de surfactantes não interfere na produção de lipases e vice-versa. Colla et al. (2010) também demonstraram em estudos realizados com Aspergillus sp. que a obtenção destes biocompostos é possível em um único bioprocesso e sugere estudos de ampliação de escala para verificação da viabilidade econômica do processo.

Ainda não foi estudado em nosso laboratório, se estes isolados são capazes de produzir lipase e biossurfactante em um mesmo processo, todavia, os resultados obtidos são promissores, uma vez que identificar um microrganismo capaz de sintetizar os dois produtos em processos a base de substratos apolares, possibilita sua aplicação em distintos processos industriais, bem como na descontaminação de ambientes contendo compostos apolares.

\subsection{Tensão superficial}

Os fungos LEB 025, 031, 035, 037, 043 e 044 foram submetidos a leitura da tensão superficial e submetidos ao Teste de Tukey ao nível de 5\% de significância para a comparação entre as médias. Estes fungos apresentaram resultado positivo de atividade enzimática em pelo menos um dos testes enzimáticos e nos dois testes de produção de biossurfactantes aplicados. $\mathrm{Na}$ Tabela 2 são apresentados os valores de tensão superficial para os isolados selecionados.
Tabela 2. Valores de tensão superficial para os isolados selecionados

\begin{tabular}{cc}
\hline $\begin{array}{c}\text { Isolado } \\
\text { LEB }\end{array}$ & $\begin{array}{c}\text { Tensão } \\
\text { superficial }\left(\mathrm{mN} \cdot \mathrm{m}^{-1}\right)\end{array}$ \\
\hline 025 & $51,8 \pm 0,1^{\mathrm{b}}$ \\
031 & $55,9 \pm 0,2^{\mathrm{c}}$ \\
035 & $49,0 \pm 0,2^{\mathrm{a}}$ \\
037 & $49,0 \pm 0,2^{\mathrm{a}}$ \\
043 & $59,8 \pm 0,2^{\mathrm{d}}$ \\
044 & $55,4 \pm 0,5^{\mathrm{c}}$ \\
\hline
\end{tabular}

Letras iguais na coluna não diferem significativamente $(\mathrm{p}<0,05)$.

Tensão superficial da água destilada $72 \mathrm{mN} . \mathrm{m}^{-1}$

De acordo com os resultados apresentados na Tabela 2 e dentro das condições estudadas, não houve diferença significativa na redução da tensão superficial entre os fungos LEB 035 e 037, sendo estes os responsáveis pelas maiores reduções da tensão superficial, $\quad(49,0$ $\left.\mathrm{mN} \cdot \mathrm{m}^{-1}\right)$ seguido do LEB 025, $(51,8$ $\left.\mathrm{mN} . \mathrm{m}^{-1}\right)$ significativamente diferente dos demais fungos. De acordo com Willumsen e Karlson, (1997) um microrganismo é apontado como potencial na produção de biossurfactante, cuja capacidade de reduzir a tensão superficial de um meio de cultivo seja $\geq 20 \mathrm{mN} \cdot \mathrm{m}^{-1}$ em comparação à água destilada $\left(72 \mathrm{mN} \cdot \mathrm{m}^{-1}\right)$. Esta definição foi adaptada, passando a ser considerada uma cultura promissora na produção de biossurfactantes aquelas cuja redução da tensão superficial de um líquido atinja valores de redução de $40 \mathrm{mN} \cdot \mathrm{m}^{-1}$ ou mais (Willumsen e Karlson, 1997). Os valores obtidos de redução da tensão superficial, neste estudo, não atingiram a faixa de $40 \mathrm{mN} \cdot \mathrm{m}^{-1}$. Isto pode ser decorrente do meio de cultivo e das condições do processo testadas não estarem ajustadas para estes microrganismos, ainda desconhecidos taxonomicamente, visto que os meios de cultivo e as condições de processo influenciam diretamente no tipo e na quantidade de biossurfactante produzido (Gudiña et al. 2015). Esse fato pode ser verificado no trabalho de Santos et al. (2013), onde a levedura Candida lipolytica foi cultivada em 13 diferentes composições de meios de cultivo durante 144 horas em 
frascos agitados, sendo observado uma variabilidade significativa do abaixamento da tensão superficial entre os meios testados. Obteve-se como o menor valor $27,7 \mathrm{mN} \cdot \mathrm{m}^{-1}$ e o maior valor de tensão superficial foi de $60,2 \mathrm{mN} \cdot \mathrm{m}^{-1}$.

Existe a possibilidade de ter ocorrido uma degradação das moléculas tensoativas, ocasionada pelos fungos, ou até mesmo, um consumo destas moléculas pelo microrganismo, conforme sugerido por Pinto (2008), que realizou um estudo comparativo do fungo Aspergillus fumigatus e da bactéria Corynebacterium aquaticum. Os valores de tensão superficial apresentados para o fungo foram na faixa de $55 \mathrm{mN} \cdot \mathrm{m}^{-1}$ à $58 \mathrm{mN} \cdot \mathrm{m}^{-1}$ após 6 dias de cultivo, enquanto a bactéria apresentou valores entre $32 \mathrm{mN} \cdot \mathrm{m}^{-1}$ e $34 \mathrm{mN} . \mathrm{m}^{-1}$ no mesmo período. Uma redução significativa da tensão superficial no estudo de Pinto (2008) pelo fungo pôde ser verificada após 24 horas de fermentação $\left(39,8 \mathrm{mN} \cdot \mathrm{m}^{-1}\right)$. Após este período, houve um aumento expressivo da tensão, fato discordante apresentado pela bactéria, que reduziu a tensão superficial para aproximadamente $38 \mathrm{mN} . \mathrm{m}^{-1}$ após 24 horas de cultivo com redução continuada até $o$ final da fermentação, com reduções na faixa de $33 \mathrm{mN} \cdot \mathrm{m}^{-1}$. A bactéria Bacillus subtilis no estudo realizado por Vaz et al. (2012), também apresentou redução da tensão superficial do meio de cultivo mais acentuada, 29,0 mN.m ${ }^{-1}$ e para Aparna et al. (2012) utilizando Pseudomonas sp. 2B, houve uma redução da tensão superficial para $30,14 \mathrm{mN} . \mathrm{m}^{-1}$.

Estes dados sugerem que as bactérias, em sua maioria, produzem moléculas com baixa massa molecular, como glicolipídeos ou lipopeptídios, que são mais eficientes na redução da tensão superficial e interfacial. Moléculas de alta massa molecular, como polissacarídeos, lipopolissacarídeos, lipoproteínas, são pouco eficientes na redução da tensão superficial, mas são capazes de promover maiores capacidades emulsificantes (Krepsky, 2004; Colla et al. 2010). As moléculas de alta massa molecular são produzidas por um grande número de espécies bacterianas e fúngicas, nos quais podem ter sido sintetizadas pelos fungos isolados testados neste trabalho. Estudos de caracterização da molécula são necessários para comprovar esta hipótese.

\subsection{Identificação produtores de biossurfactante \\ dos fungos lipase $e$}

Os isolados LEB 025, 037 e 044, selecionados como potenciais produtores concomitante de lipase e biossurfactante foram sujeitos a identificação através das suas características macroscópicas (visual) e microscópicas (MEV). O isolado LEB 025, identificado como Aspergillus niger (Figura 2), foi o microrganismo com maior número de variáveis distintas macromorfológicamente dentre os isolados, sendo também, o único cuja coloração dos esporos apresentou intensa pigmentação preta, com superfície rugosa no verso da colônia, após sete dias de cultivo. Os fungos LEB 037 e 044 apresentaram coloração branca com pequenos esporos visíveis, identificados microscopicamente como sendo do gênero Rhizopus. 

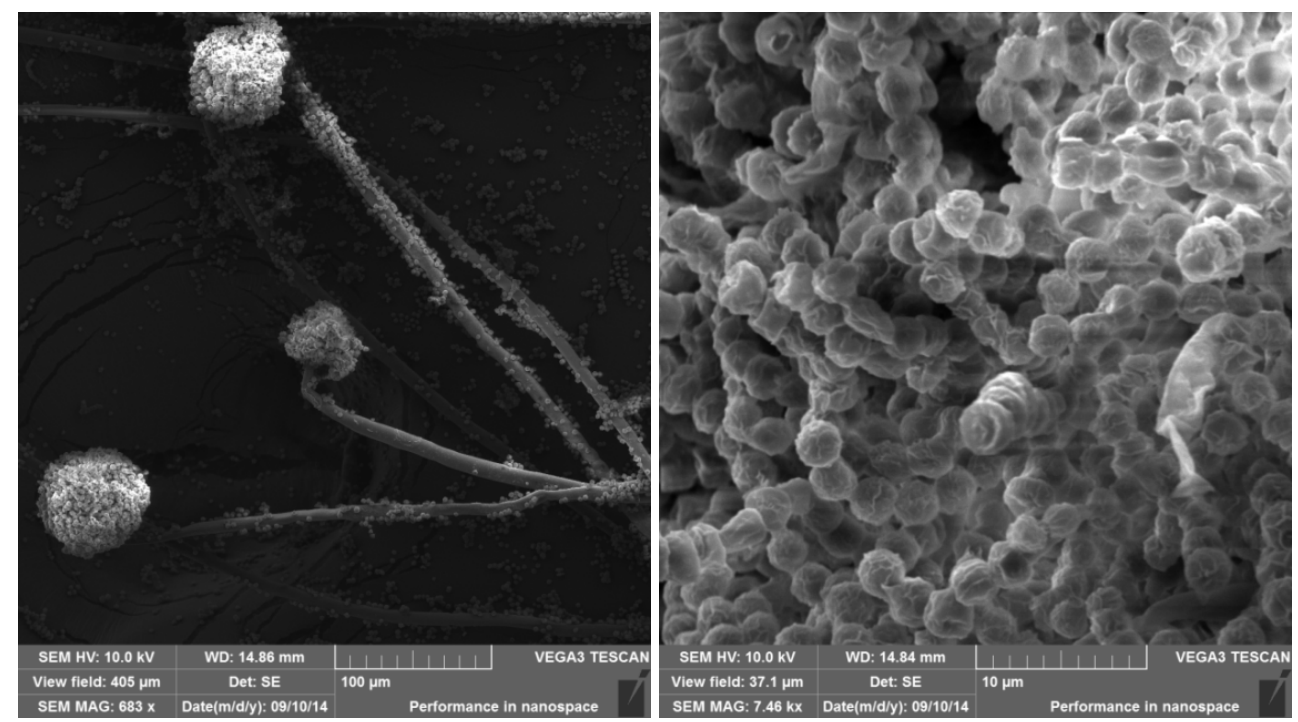

Figura 2. Microscopia eletrônica de varredura do isolado LEB 025 (A) e seus esporos (B)

\section{CONCLUSÕES}

O potencial de produção de lipases e biossurfactantes por fungos filamentosos, procedentes de resíduos de refinarias de óleo vegetal e de petróleo, foi avaliado mediante a realização de testes qualitativos. Entre os 24 fungos filamentosos isolados, somente os fungos LEB 025, 037 e 044, apresentaram resultados positivos quanto a atividade lipolítica e presença de biossurfactantes, sugerindo a possibilidade de uma produção concomitante de ambos os compostos, identificados como Aspergillus niger (LEB 025) e Rhizopus sp. (LEB 037 e 044), sendo considerados

\section{REFERÊNCIAS}

ALVES, E. N. 2003. Red Blood Cell (RBC) Teste de hemólise: uma alternativa ao teste de Draize-Irritação ocular na avaliação do poder tóxico de produtos cosméticos no controle de qualidade. Dissertação de Mestrado, Instituto Nacional de Controle de Qualidade em Saúde - FIOCRUZ.

APARNA, A., SRINIKETHAN, G., SMITHA, H. 2012. Production and characterization of biosurfactant produced como possíveis candidatos para posteriores estudos de otimização e aumento de escala do bioprocesso.

\section{AGRADECIMENTOS}

Os autores agradecem o apoio financeiro do Conselho Nacional de Desenvolvimento Científico e Tecnológico $(\mathrm{CNPq})$, da Fundação Coordenação de Aperfeiçoamento de Pessoal de Nível Superior (CAPES) e ao Programa conjunto de pesquisa Brasil-Espanha, Programa CAPES/DGU.

by a novel Pseudomonas sp. 2B. Colloids Surfaces B Biointerfaces, 95, 9-23.

ARAUJO, L. V., FREIRE, D. M. G. 2013. Biossurfactantes: anticorrosivas, antibiofilmes Propriedades antimicrobianas. Quimica Nova, 36, 848858.

ARUN, A., EYINI, M. 2011. Comparative studies on lignin and polycyclic aromatic hydrocarbons degradation by 
basidiomycetes fungi. Bioresource Technology, 102, 8063-8070.

BANAT, I.M., 1993. The isolation of thermophilic biosurfactant producing Bacillus sp. Biotechnology. Letters. 15, 591- 594.

BURKERT, J. F. M.; MAUGERI, F.; RODRIGUES, M. I. 2004. Optimization of extracelular lipase production by Geotrichum sp. using factorial design. Bioresource Technology, 91, 77-84.

CARDENAS, F., DE CASTRO, M. S., SANCHEZ-MONTERO, J. M., SINISTERRA, J. V., VALMASEDA, M., ELSON, S. W., ALVAREZ, E. 2001. Novel Microbial lipases: catalytic activity in reactions on organic media. Enzyme and Microbial Technology. 28, 45-154.

CARRILLO, P. G., MARDARAZ, C., PITTA-ALVAREZ, S. J., GIULIETTI, A. M. 1996. Isolation and selection of biosurfactant - producing bacteria. World Journal of Microbiology and Biotechnology, 12, $82-84$.

CASTIGLIONI, G. L., BERTOLIN, T. E., COSTA, J. A. V. 2009. Produção de biossurfactante por Aspergillus fumigatus utilizando resíduos agroindustriais como substrato. Química Nova, 32, 292-295.

CHAHINIANA, H. e SARDA, L. 2009. Distinction Between Esterases and Lipases: Comparative Biochemical Properties of Sequence-Related Carboxylesterases. Protein \& Peptide Letters, 16, 1149-1161

CHEN, C., BAKER, S. C., DARTON, R. C. 2007. The application of a high throughput analysis method for the screening of potential biosurfactants from natural sources. Journal of microbiological methods, 70, 503-510.

COLLA, L. M., HEMKERMEIER, M., GIL, A. S. L. 2012. Biossorção de cádmio e produção de biossurfactantes por fungos filamentosos em fermentação submersa. Revista CIATEC - UPF, 4, 1-10.

COLLA, L. M., RIZZARDI, J., PINTO, M. H., REINEHR, C. O., BERTOLIN, T. E., COSTA, J. A. V. 2010. Simultaneous production of lipases and biosurfactants by submerged and solid-state bioprocess. Bioresource Technology, 101, 8308-8314.

CORTÉS, S. A. D. J., MOSQUEDA, O. T. 2013. Una mirada a los organismos fúngicos: Fábricas versátiles de diversos metabolitos secundários de interés biotecnológico. Revista Quimica Viva, 6490.

DESAI, J. D., BANAT, I. M. 1997. Microbial Production of Surfactants and their Commercial Potential. Microbiology and Molecular Biology Reviews, 61, 47-64.

ESPOSITO, E., AZEVEDO, J. L. 2004. Fungos uma introdução à biologia, bioquímica e biotecnologia, Caxias do Sul, Educs.

GASPARIN, F. G. M., MAGRI, A., NEVES, A. F., CELligoI, M. A. P. C. 2012. Produção de Lipase e Biossurfactante por isolado de Efluente de Laticínio. Biochemistry and Biotechnology Reports, DOI 10.5433/2316-5200.2012 1: 28-31.

GUDIÑA, E. J., RANGARAJAN, V., SEN, R., RODRIGUES, L. R. 2013. Potential therapeutic applications of biosurfactants. Trends in Pharmacological Sciences, 34, 667-675.

GUDIÑA, E. J, RODRIGUES, A. I., ALVES, E. DOMINGUES, M. R. TEIXEIRA, J. A., RODRIGUES, L. R. 2015. Bioconversion of agro-industrial byproducts in rhamnolipids toward applications in enhanced oil recovery and bioremediation. Bioresource Technology, 177, 87-93.

KOUKER, G., JAEGER, K. 1987. Specific and sensitive plate assay for bacterial 
lipases. Applied and environmental microbiology, 53, 211-213.

KREPSKY, N. 2004. Produção de biossurfactantes por consórcios bacterianos hidrocarbonoclásticos. Dissertação de Mestrado, Universidade Federal Fluminense.

KUMAR, D., KUMAR, L., NAGAR, S., RAINA, C., PARSHAD, R., GUPTA, V. K. 2012. Screening, isolation and production of lipase/esterase producing Bacillus sp. strain DVL2 and its potential evaluation in esterification and resolution reactions. Archives of Applied Science Research, 4, 1763-1770.

MARTINS, V. G., KALIL, S. J., COSTA, J. A. V. 2008. Co-produção de lipase e biossurfactante em estado sólido para utilização em biorremediação de óleos vegetais e hidrocarbonetos. Quimica Nova, 31, 1942-1947.

MATSUURA, A. B. J. 2004. Produção e caracterização de biossurfactantes visando a aplicação industrial e em processos de biorremediação. Tese de Doutorado, Universidade Estadual de Campinas / Faculdade de Engenharia de Alimentos, Campinas.

Mulligan, C.N., Cooper, D.G., Neufeld, R.J., 1984. Selection of microbes producing biosurfactants in media without hydrocarbons. Journal of Fermentation Technology. 62, 311-314.

NITSCHKE, M., PASTORE, G. M. 2002. Biossurfactantes: Propriedades e Aplicações. Quimica Nova, 25,772-776.

PACHECO, S. M. V. 2012. Produção, Caracterização e Imobilização de Lipase de Fungo Filamentoso isolado de efluente de abatedouro de frangos. Tese de Doutorado, Universidade Federal de Santa Catarina.

PANDA, T., GOWRISHANKAR, B. S. 2005. Production and applications of esterases. Applied Microbiology and Biotechnology, 67, 160-169.

PARASZKIEWICZ, K., KANWAL, A., DLUGONSKI, J. 2002. Emulsifier production by steroid transforming filamentous fungus Curvularia lunata. Growth and product characterization. Journal of Biotechnology, 92, 287-294.

PINTO, M. H. 2008. Produção de biossurfactantes bacteriano e fúngico por fermentação em estado sólido e submersa utilizando resíduos agroindustriais. Dissertação de Mestrado, Universidade Federal do Rio Grande.

PLAZA， G. A., ZJAVIONY, I. Z., BANAT, I. M. 2006. Use of different methods for detection of thermophilic biosurfactant-producing bacteria from hydrocarbon-contaminated and bioremediated soils. Journal of Petroleum Science and Engineering, 50, 71-77.

PLOU, J. P., FERRER, M., NUERO, O. M., CALVO, M. V., ALCALDE, M., REYES, F., BALLESTEROS, A. 1998. Analysis of Tween 80 as an esterase/lipase substrate for lipolytic activity assay. Biotechnology Techniques, 12 (3): 183 186.

RAPP, P., BACKHAUS, S. 1992. Formation of extracellular lipases by filamentous fungi, yeast and bacteria. Enzyme Microbiology and Technology, 14, 938-943.

ROVEDA, M., HEMKERMEIER, M., COLLA, L. M. 2010. Avaliação da produção de lipases por diferentes cepas de microrganismos isolados de efluentes de laticínios por fermentação submersa. Ciência e Tecnologia de Alimentos, 30, 126-131.

SAHARAN, B. S., SAHU, R. K., SHARMA, D. 2012. A Review on Biosurfactants: Fermentation, Current 
Developments and Perspectives. Genetic Engineering and Biotechnology Journal, 2011GEBJ-29: 1-14.

SANTOS, D. K. F., RUFINO, R. D., LUNA, J. M., SANTOS, V. A., SALGUEIRO, A. A. 2013. Synthesis and evaluation of biosurfactant produced by Candida lipolytica using animal fat and corn steep liquor. Journal of Petroleum Science and Engineering, 105, 43-50.

SIERRA, G. 1957. A simple method for the detection of lipolytic activity of microorganisms and some observations on the influence of the contact between cells and fatty substrates. Antonie van Leeuwenhoek, $23,15-22$.

SPOECKNER, S.; WRAY, V.; NIMTZ, M.; LANG, S. 1999. Glycolipids of the smut fungus Ustilago maydis from cultivation on renewable resources. Applied Microbiology and Biotechnology. 51: 33-39.

VAZ, D. A., GUDIÑA, E. J., ALAMEDA, E. J., TEIXEIRA, J. A., RODRIGUES, L. R. 2012. Performance of a biosurfactant produced by a Bacillus subtilis strain isolated from crude oil samples as compared to commercial chemical surfactants. Colloids and Surfaces B: Biointerfaces, 89, 167-174.

WILLUMSEN, P. A., KARLSON, U. 1997. Screening of bacteria, isolated from PAH-contaminated soils, for production of biosurfactants and bioemulsifiers. Biodegradation, 7,415-423.

YOUSSEF, N. H., DUNCAN, K. E., NAGLE, D. P., SAVAGE, K. N., KNAPP, R. M., MCINERNEY, M. J. 2004. Comparison of methods to detect biosurfactant production by diverse microorganisms. Journal of Microbiological Methods, 56, 339-347. 